\begin{tabular}{|l|l|l|l|l|l|}
\hline MUNIBE Antropologia-Arkeologia & $n^{\circ} 69$ & $177-190$ & DONOSTIA & 2018 & ISSN 1132-2217 • elSSN 2172-4555 \\
\hline
\end{tabular}

\title{
El yacimiento calcolítico de Karea en el contexto de las cuevas sepulcrales de Gipuzkoa (País Vasco)
}

\author{
The Chalcolithic site of Karea in the context \\ of burial caves in Gipuzkoa (Basque Country)
}

PALABRAS CLAVES: Calcolítico; inhumación; ajuar funerario; antracología; isótopos. GAKO-HITZAK: Kalkolitoa; ehorzketa; hileta hatua; antrakologia; isotopoak. KEY WORDS: Chalcolithic; burial; grave goods; anthracology; isotopes.

\section{Ainhoa ARANBURU-MENDIZABAL(1), Izaskun SARASKETA-GARTZIA(1), Alvaro ARRIZABALAGA(1), Domingo C. SALAZAR-GARCíA ${ }^{(1,3,5)}$, ANTXIETA ARKEOLOGIA TALDEA ${ }^{(4)}$ y $\mathrm{M}^{\mathrm{a}}$ José IRIARTE-CHIAPUSSO ${ }^{(1,2)}$}

\section{RESUMEN}

En el yacimiento arqueológico de Karea (Aia, Gipuzkoa), integrado por las cavidades contiguas de Karea-A y Karea-B, se recuperaron numerosos restos cerámicos y faunísticos (Karea-A) y vestigios de una inhumación calcolítica (Karea-B). El presente trabajo se ha vertebrado en dos ejes. En primer lugar, el estudio de ambos depósitos mediante diferentes disciplinas: (1) estudio antropológico; (2) estudio del ajuar, compuesto por restos cerámicos y faunísticos; (3) identificación antracológica de los restos leñosos recuperados en el depósito funerario y por último, (4) estudios isotópicos que nos han permitido obtener datos de la alimentación $\left(\delta^{13} \mathrm{C}\right.$ y $\left.\delta^{15} \mathrm{~N}\right)$ y procedencia $\left({ }^{87} \mathrm{Sr} /{ }^{86} \mathrm{Sr}\right)$ del sujeto inhumado en el yacimiento. En segundo lugar, siendo este el objetivo preferente de este trabajo, contextualizar y establecer una comparativa con otras manifestaciones sepulcrales prehistóricas en cueva de la región.

\section{LABURPENA}

Karea-A eta Karea-B haitzuloez konposatutako historiaurreko Kareako (Aia, Gipuzkoa) aztarnategi arkeologikoan, zeramika, fauna zein kalkolitoko ehorzketa baten aztarnak berreskuratu ziren. Honako lan honek ondorioz, bi ardatz ditu. Alde batetik, deposituen azterketa diziplina desberdinen bidez: (1) azterketa antropologikoa; (2) hatua osatzen duten zeramika nahiz fauna aztarnen azterketa; (3) ehorzketan berreskuratutako egur-ikatzen behaketa eta, (4) ehortzitako gizabanakoaren elikaduraren $\left(\delta^{13} \mathrm{C}\right.$ y $\left.\delta^{15} \mathrm{~N}\right)$ eta jatorriaren $\left({ }^{87} \mathrm{Sr} /{ }^{86} \mathrm{Sr}\right)$ inguruan berri ematen diguten analisi isotopikoak. Bestetik, eta artikulu honen helburu nagusi izanez, kobazuloa bere testuinguruan kokatu zein, eskualdean dauden gainontzeko ehorzketa kobazuloekin alderaketa burutu.

\section{ABSTRACT}

Archaeological site of Karea (Aia, Gipuzkoa) was discovered in 2007 by Antxieta Jakintza Taldea (a Basque cultural-speleological aggrupation from Azpeitia -Gipuzkoa-). This site has two contiguous cavities where different archaeological remains were discovered: Karea-A and Karea-B. Karea-A, which has small dimensions and an easy entrance, was excavated in 2008 by Antxieta Jakintza Taldea and Maria José Iriarte-Chiapusso (archaeologist and IKERBASQUE researcher). Faunal remains and abundant pottery remains were recovered there, suggesting a short time human occupation during prehistorical times. At the same time, the speleological group found a second cave which has a small and hidden entrance: Karea-B. The researchers supposed that the cavities were linked in the past, but, an internal collapse divided both caves. They also found some human bones in a small side gallery. The excavation of Karea-B in 2009 resulted in the discovery of a chalcolithic inhumation. Some pottery and fauna remains, which were identified like grave goods, were also found with the human body. Under this burial, charcoal fragments were recovered, suggesting a ritual or hygienic aim because there is no fire signal into the bones. We here present a multidisciplinary study of this archaeological deposit consisting of: (1) anthropological study; (2) pottery and faunal grave good assemblage study; (3) anthracological study of the wood recovered at the burial; (4) isotopic study to gain information on diet $\left(\delta^{13} \mathrm{C}\right.$ and $\left.\delta^{15} \mathrm{~N}\right)$ and provenance $\left({ }^{87} \mathrm{Sr} /{ }^{86} \mathrm{Sr}\right.$ ) from the buried individual. Finally, we have contextualized this new finding amongst other cave burials from Gipuzkoa and especially in Urola Valley.

\footnotetext{
(1) Consolidated Research Group of Prehistory (IT-622-13). Centro de Investigación Micaela Portilla Ikergunea. C/ Justo Vélez de Elorriaga, 1 (01006, Vitoria-Gasteiz). Universidad del País Vasco/Euskal Herriko Unibertsitatea (UPV/EHU).

(2) IKERBASQUE. Basque Foundation for Science. Laboratorio de Paleobotánica Lydia Zapata Paleobotanikako Laborategia. C/ Tomás y Valiente s/n (01006, Vitoria-Gasteiz). Universidad del País Vasco/Euskal Herriko Unibertsitatea (UPV/EHU).

(3) Department of Geological Sciences. Science Faculty. Level 6, PH Hahn Building. Upper Campus, University of Cape Town (Cape Town, South Africa).

(4) Soreasu Kultura Zentroa. Soreasu Auzunea (20730, Azpeitia).

(5) IKERBASQUE. Basque Foundation for Science.
} 


\section{INTRODUCCIÓN}

El territorio de Gipuzkoa, a pesar de sus reducidas dimensiones, alberga unos 250 yacimientos arqueológicos o paleontológicos (Tapia y Ceberio, 2011) en cueva. De ese total, 95 corresponderían a cuevas de uso sepulcral (Sarobe, 2012). El estudio de este tipo de cavidades se desarrollará principalmente durante el siglo XX y pueden diferenciarse tres etapas distintas (Mujika y Edeso, 2011). La primera etapa va del siglo XIX a 1927, cuando se realizan las primeras investigaciones en cueva y se descubren, entre otras, Orkatzategi, Iruaxpe I o Urtao II. Entre 1927 y 1970 y con la excavación de Jentiletxeta por parte de J.M. Barandiarán, se dará inicio a la segunda etapa que destacará por la exploración, excavación sistemática e introducción de una metodología científica en la investigación de las cuevas; excavándose entre otras: Urtiaga, Jentiletxeta II, Marizulo, etc y descubriendo, por ejemplo, Arantzazu. La tercera etapa, que abarca desde los 70 hasta la actualidad, resulta la más fructífera por varias razones. Junto al hallazgo de yacimientos por parte de grupos culturales y espeleológicos, tales como Antxieta Jakintza Taldea (conocido en la actualidad como Antxieta Arkeologia Taldea) de Azpeitia, Munibe Taldea de Azkoitia o Aloña Mendi de Oñati, se llevarán a cabo las primeras excavaciones en extensión en Urtao II, Iruaxpe I o Nardakoste IV. Se publican además las primeras tesis o trabajos de síntesis: Apellániz (1973) o Armendariz y Etxeberria (1983, 1995). Todo ello, junto a los nuevos hallazgos arqueológicos realizados a lo largo de la primera década del siglo XXI, como sería el caso de Karea, ha permitido la caracterización de las cuevas sepulcrales como un fenómeno funerario particular.
El presente artículo tiene como objetivo principal contextualizar el yacimiento de Karea dentro de las manifestaciones funerarias en cueva de Gipuzkoa; incidiendo en especial, y por situarse dentro del mismo, en el valle del Urola.

\section{DESCRIPCIÓN DE KAREA E INVESTIGACIÓN DE CAMPO}

El yacimiento de Karea consta de dos cavidades contiguas: Karea-A y Karea-B. Karea-A fue localizada en 2007 por el grupo de espeleología Antxieta Arkeologia Taldea en la ladera nororiental del monte Kareaga (Galán y Goikoetxea, 2002) del barrio de Iturriotz (Aia, Gipuzkoa). Esta cavidad, cuya entrada está semi-obstruida por grandes bloques de piedra, dispone de una única galería de 29 metros que está cubierta por concreciones estalagmíticas (Antxieta Jakintza Taldea, 2009) (figura 1). La primera intervención arqueológica, una cata realizada a cinco metros de la entrada, fue llevada a cabo en 2008 por Antxieta Arkeologia Taldea y María José Iriarte-Chiapusso. Distribuido en tres niveles arqueológicos bajo la concreción estalagmítica (en la actualidad sólo existe tierra en la rampa de acceso) se halló un conjunto de cerámicas fragmentadas junto a algunos restos faunísticos. El sondeo se dio por terminado cuando a 0,25 metros afloró la roca madre.

Finalizada la intervención arqueológica y una vez en el exterior, los miembros de Antxieta Arkeologia Taldea y M.J. Iriarte-Chiapusso localizaron a unos 20 metros de la entrada de Karea-A el acceso a una segunda cavidad. Esta segunda cueva, a la que se accedía bajando por una estrecha sima de aproximadamente cinco me-

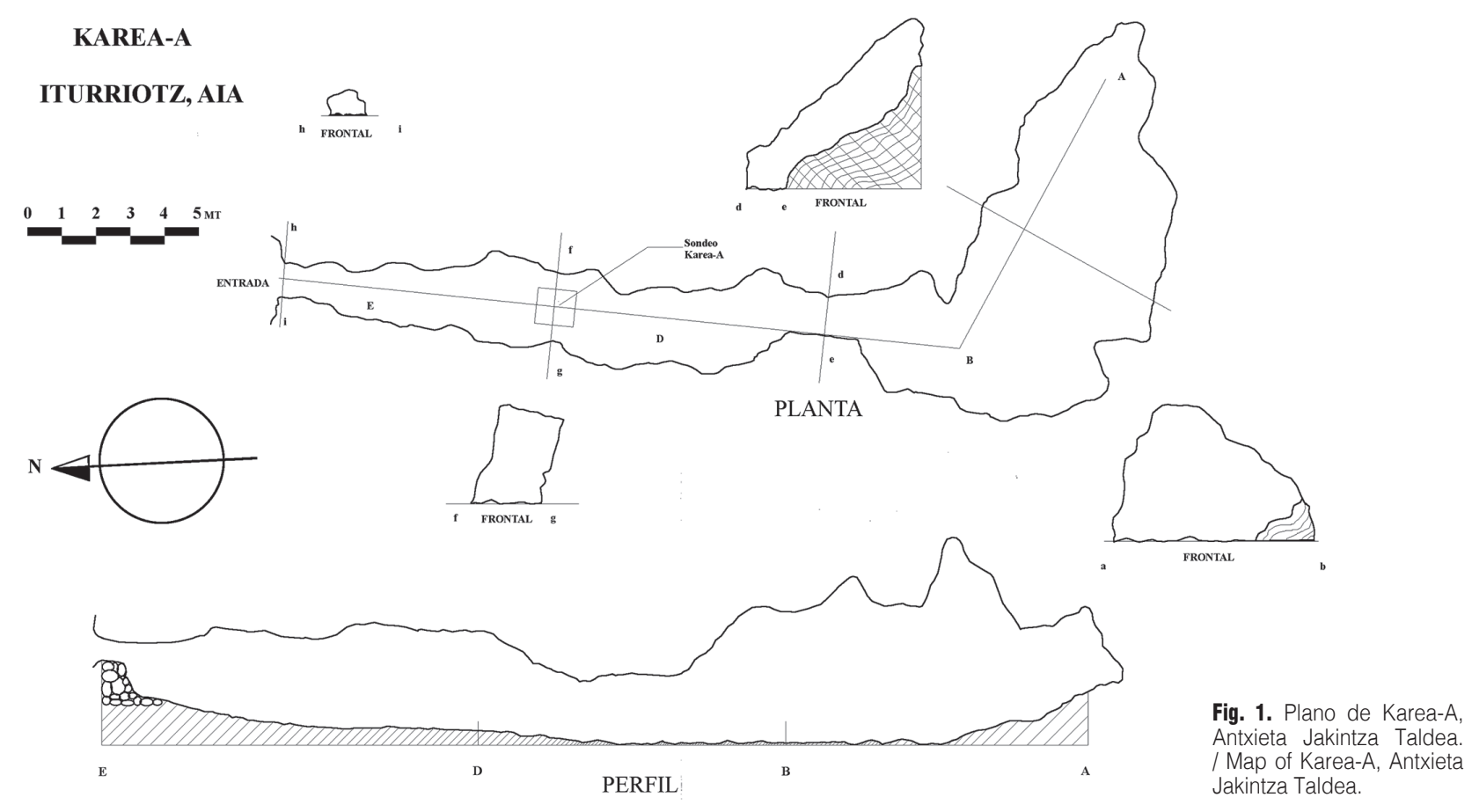


tros de altura y a la que denominaron Karea-B, resultó ser más amplia que la anterior y se desarrollaba en al menos tres niveles (figura 2). Durante su exploración no se detectó acceso alguno a Karea-A, pero su disposición contigua así, como la presencia de un derrumbe en una de las paredes que ambas comparten, parece indicar que en algún momento estuvieron interconectadas mediante una galería horizontal. En una gatera lateral, situada a unos 10 metros de la actual entrada, fueron identificados lo que parecían ser huesos humanos, huesos de bóvido y un gran fragmento de cerámica. Asimismo, en una minúscula galería situada junto a la gatera se recuperaron otros fragmentos cerámicos. Teniendo en cuenta el hallazgo, en el año 2009 se llevaron a cabo dos nuevos sondeos de $1 \mathrm{~m} 2$ cada uno (Iriarte-Chiapusso, 2010). El primer sondeo, de aproximadamente 0'90 metros de profundidad y denominado Karea-B-1, se realizó en la gatera lateral donde distribuidos en un total de 13 niveles arqueológicos se recuperaron huesos de origen humano, de origen animal, varios fragmentos cerámicos y se identificó la presencia de carbones. El segundo sondeo, Karea-B-2, se realizó cerca del derrumbe pero tras excavar cerca de 1'75 metros se confirmó que era arqueológicamente estéril.

\section{ESTUDIO DE KAREA}

Los materiales arqueológicos del yacimiento Karea fueron gestionados por Antxieta Arkeologia Taldea hasta su depósito final en GORDAILU: Centro Cultural del Patrimonio Mueble de Gipuzkoa (Irun). Dichos materiales, previo a su entrega, fueron depositados de manera provisional en los Laboratorios de Prehistoria del Departamento de Geografía, Prehistoria y Arqueología de la UPV-EHU (Vitoria-Gasteiz) donde se llevaron a cabo diversos estudios: cerámicos y faunísticos para los materiales del sondeo Karea-A y antracológicos, cerámicos, faunísticos, antropológicos e isotópicos para los de Karea-B.

\subsection{Karea-A}

\subsubsection{EsTUdio CERÁMICO}

La metodología empleada en este caso, tanto para los fragmentos recuperados en Karea-A como en Karea-B, fue la descripción de las pastas y formas así como la medición de aquellos fragmentos que podrían ser identificables. En la excavación se recuperaron un total de 54 fragmentos cerámicos y en el proceso de

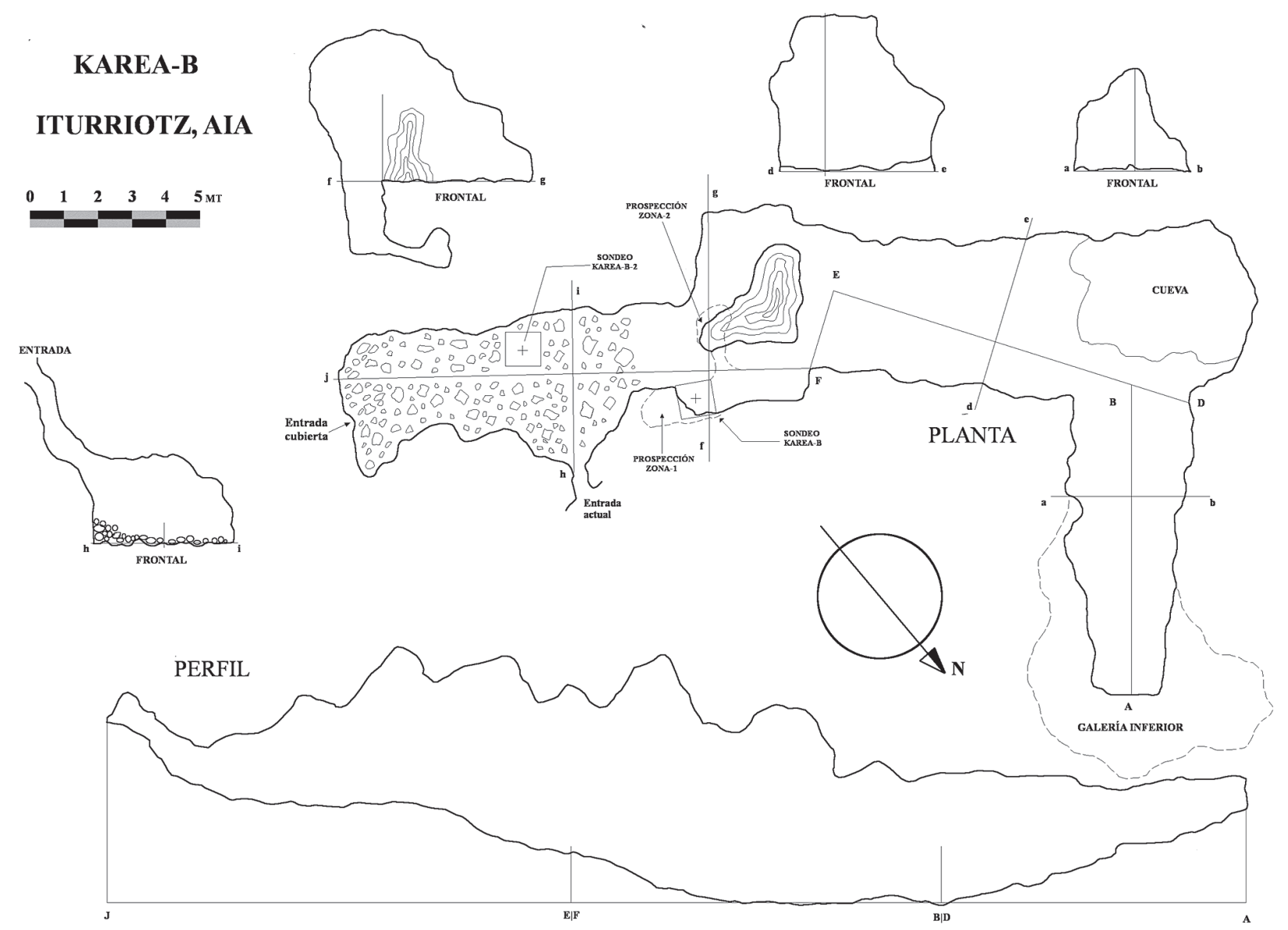

Fig. 2. Plano de Karea-B, Antxieta Jakintza Taldea. / Map of Karea-B, Antxieta Jakintza Taldea. 
cribado 30 fragmentos más. Estos restos cerámicos además de estar bastante concreciones eran de tamaño pequeño (inferiores a cuatro centímetros) por tanto no se pudo establecer la morfología de los mismos: 82 de los fragmentos fueron clasificados como informes, otro como dudoso (podría pertenecer a un fondo) y un único fragmento resultó identificable siendo clasificado como un borde (figura 3). Los recipientes de origen estarían hechos a mano y en lo referente a la cocción y coloración de la pasta, se establecieron dos agrupaciones:

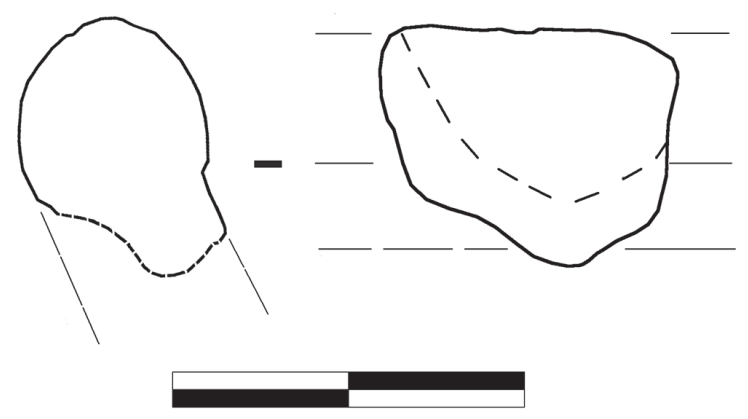

Fig. 3. Ilustración del borde cerámico recuperado en Karea-A. / Ceramic rim recovered in Karea- $A$.

a) Fragmentos de coloración monocromática negra -indicativa de una cocción reductora- y en los que se apreciaba que la pasta estaba alisada. El borde recuperado, así como el dudoso fondo, presentaban esta composición y corresponderían a un recipiente de modestas dimensiones.

b) Fragmentos de composición mixta -cocción reductora al interior y oxidante al exterior- en los cuales pueden diferenciarse otros dos subgrupos: 1) aquellos que estaban compuestos por una pasta negra lisa en el interior, y de aspecto terroso y coloración rojiza en el exterior y 2) los que mostraban una tonalidad marrón en el exterior, pudiendo corresponder a una capa de engobe.

Debido a su pequeño tamaño y nivel de fragmentación, no fue posible detectar ningún otro tipo de decoración aparte de la mencionada decoración plástica del segundo conjunto pero basándonos en los datos expuestos pudimos establecer que los restos cerámicos recuperados corresponderían a un mínimo de tres recipientes.

\subsubsection{Estudio faunístico}

El estudio faunístico, tanto de Karea-A como de Karea-B, se basó en la identificación anatómica de los huesos con el fin de establecer si estos podían aportar información útil de cara a identificar las especies a las que pertenecían (König y Liebich, 2004; France, 2009). Los huesos recuperados, e identificados, en Karea-A fueron los siguientes: un fragmento de costilla de gran tamaño que posiblemente perteneciese a un bóvido, siete fragmentos de costilla de menor tamaño que podrían corresponder a un ovicáprido y dos dientes sin corona atribuidos también a esa última especie.

\subsection{Karea-B.}

\subsubsection{Estudio ANTRACOLÓGICO}

El principio técnico de la Antracología está basado en la observación directa de los fragmentos de carbón. Precedido todo ello por la recuperación de los restos arqueobotánicos y una correcta estrategia de muestreo que se ajuste a las características del yacimiento, así como al volumen de sedimento recuperado (Zapata y Peña-Chocarro, 2013). En el caso de Karea-B, al tratarse de una cata arqueológica y ser la combustión resultado de una acción humana concreta, se recogió in situ en bolsas de almacenaje una pequeña muestra por cada capa (capas 10-13). Estas bolsas fueron debidamente referenciadas para ser posteriormente procesadas en el Laboratorio de Paleobotánica Lydia Zapata de la UPV-EHU.

Las muestras presentaban un sedimento muy arcilloso que imposibilitaba la completa recuperación del material leñoso. Al tratarse de muestras pequeñas, la estrategia empleada fue la de verter el contenido en pequeños recipientes con una malla de 125 micras y con agua destilada. Disuelto el sedimento de las muestras los carbones de mayor tamaño fueron recuperados manualmente y el resto se dejó a secar evitando su exposición a fuertes corrientes de aire o a la luz directa del sol (Caruso-Fermé, 2013). Finalizado el secado, se procedió al tamizado de las muestras empleando una torre de tamices de medidas comprendidas entre los dos milímetros y las 250 micras. La fracción $>2$ mm fue recuperada para su posterior identificación taxonómica.

La identificación de los carbones se llevó a cabo con la observación de los planos anatómicos mediante un microscopio de luz incidente OLYMPUS BX51 y con la consulta de atlas de anatomía vegetal (Schweingruber, 1990) y las colecciones de referencia del Laboratorio de Paleobotánica Lydia Zapata. Para que la identificación sea correcta el tamaño de los carbones debe ser igual o superior a los $4 \mathrm{~mm}$, aunque este límite puede situarse también en los $2 \mathrm{~mm}$ (Zapata y Peña-Chocarro, 2013). En los casos en los que no se puede hacer una determinación a nivel de especie, se opta por conceptos más amplios como por ejemplo el género, la familia o el grupo. A su vez, ha de tenerse en cuenta que la conservación de los carbones será un factor determinante en la identificación, ya que frecuentemente dificulta esta labor. En aquellos casos donde la identificación es dudosa, el término aplicado es indeterminado y cuando es imposible, indeterminable.

Los carbones recuperados en Karea muestran gran fragilidad y se hayan bastante concrecionados debido al nivel de humedad de la cueva. Estos factores han 
dificultado su identificación y solo han sido determinables a nivel de género: Quercus. La presencia de un solo género en las muestras, junto a que son resultado de una combustión concreta y puntual, no nos permite realizar una reconstrucción paleoecológica. La problemática es la misma a la hora de extrapolarlo al plano socioeconómico. Junto a las dificultades ya enumeradas, y teniendo en cuenta que por las características del yacimiento no ha sido posible realizar estudios polínicos, no puede determinarse si la selección de esta madera se dio por preferencia del grupo o por la proximidad con el yacimiento.

\subsubsection{ESTUDIO CERÁMICO}

El conjunto cerámico de Karea-B resulta menor a nivel cuantitativo pero permite extraer mayor información que el de Karea-A. Debemos mencionar que estos fragmentos fueron recuperados en el depósito funerario (zona-1) y en una pequeña gatera que se encontraba junto al mismo (zona-2). Teniendo en cuenta las características de los fragmentos recuperados puede deducirse que habría un mínimo de dos recipientes:

a) Zona-1: se recuperaron dos fragmentos de pasta de coloración negra, representativa de una cocción reductora, y en cuyas cara interior y exterior se podían apreciar finas capas de engobe de coloración marrón (posiblemente aplicadas con la función de impermeabilizar el recipiente y resultando a su vez, decorativas). Lo destacable de estos fragmentos era el reborde o carena que presentaban en la parte central (figura 4) y que podrían pertenecer a un vaso carenado de carena media o a un vaso bitroncocónico de carena media como el hallado en Sastarri II (Mujika y Edeso, 2011). En la tercera capa del sondeo se recuperó un pequeño fragmento informe de coloración anaranjada que no aportó mayor información.

b) Zona-2: se recuperaron varios fragmentos cerámicos cuya pasta era de composición mixta: oxidante al exterior y reductora al interior. En la cara interior
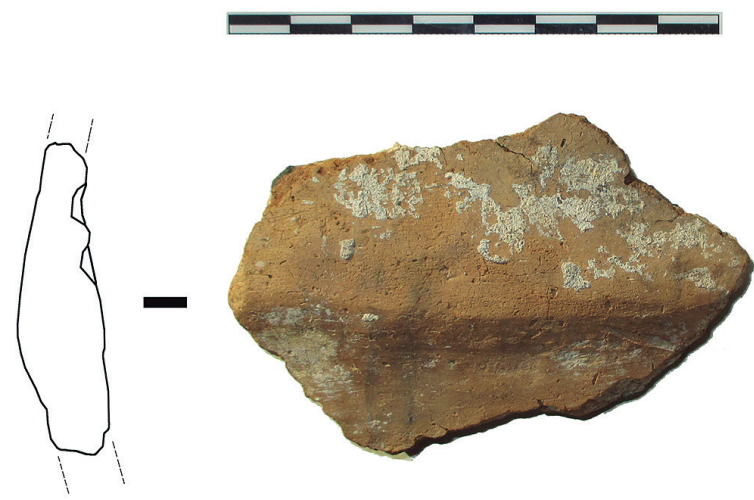

Fig. 4. Fragmento cerámico con carena recuperado en Karea-B. / Ceramic fragment with careen recovered in Karea-B. de los fragmentos se identificó una fina capa de engobe de coloración marrón y en la exterior la presencia de una decoración de barro plástica junto a varios surcos de dedos (figura 5). Estos por tanto, corresponderían a una orza de decoración plástica dedada. A pesar de no haber podido encajar todos los fragmentos entre sí, las características aquí descritas permiten deducir que en origen pertenecieron a un mismo recipiente, que además, sería de un tamaño considerable.
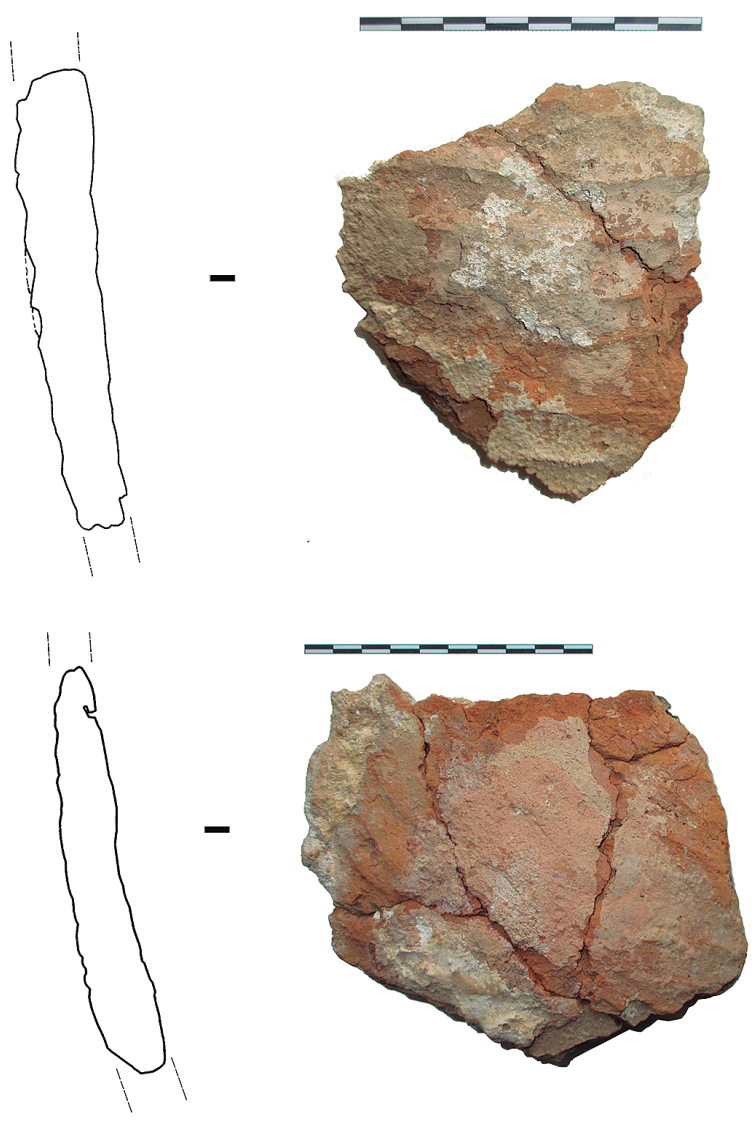

Fig. 5. Fragmentos cerámicos recuperados en Karea-B. / Ceramic frag ments recovered in Karea-B.

\subsubsection{Estudio faunístico}

El estudio de los restos faunísticos determinó que la mayoría de restos recuperados en Karea-B correspondían a un Bos taurus, siendo los huesos analizados los siguientes: un fragmento de cráneo, fragmentos de una de las escápulas, las epífisis superior e inferior de un metacarpo y varios fragmentos de mandíbula junto a algunos molares. En el proceso de identificación la mandíbula y la epífisis inferior del metacarpo, y a pesar de estar fragmentadas y concrecionadas, fueron las de mayor utilidad a la hora de determinar los restos (König y Liebich, 2004; France, 2009). En lo referente a la mandíbula, el fragmento empleado correspondía al lateral 
derecho, cuyas características sirvieron para determinar que pertenecían a un bóvido al estar la dentadura distribuida tanto en la sección frontal como lateral. Estas características anatómicas podrían corresponder a un équido, sin embargo, la curvatura de la mandíbula descartaba esa posibilidad. En el caso del metacarpo, se identificaron: a) el canal distal; b) las trocleas metacarpianas, tanto axial como abaxial y c) la incisura inter-troclear, y cuyas características correspondían a las de un bóvido. Junto a estos restos también se recuperaron huesos de un ovicáprido joven: a) parte superior de la diáfisis del fémur, b) fragmento inferior de la diáfisis de ambos húmeros y c) un metápodo sin fusionar.

\subsubsection{ESTUDIO ANTROPOLÓGICO}

El estudio antropológico fue llevado a cabo en los Laboratorios de Prehistoria de la UPV/EHU y tras la debida documentación y recomposición del esqueleto pudimos establecer que los que los restos óseos recuperados en Karea-B corresponderían a un único individuo. A pesar de que los huesos mostraban un grado de conservación desigual (fracturados, concrecionados...), al haberse recuperados huesos largos completos, la apófisis mastoide derecha o algunas piezas dentales (figura 5) pudimos determinar el sexo y estimar la edad y la estatura del individuo. Para ello se emplearon diversas fórmulas matemáticas o sistemas de clasificación (White et al., 2012). Debemos indicar que también se realizó un estudio isotópico sobre estos restos tal, y como se expone en el apartado 3.2.5 del presente artículo.

a) Sexo. Para determinar este aspecto, y a falta de huesos tan significativos como la pelvis, se analizaron las características del maxilar inferior, el temporal y se tuvieron en cuenta los parámetros métricos de determinados huesos. Recomponiendo la mandíbula se observó que la prominencia mentoide era pronunciada y la rama maxilar recta y de ángulo rugoso, características relacionas con sujetos masculinos. En lo referente a la apófisis mastoides, y basándonos en las clasificaciones relacionadas con el dimorfismo sexual (Walker, 2008 en White et al., 2012) se determinó que esta era grande y acusada. Por tanto, y teniendo en cuenta que esta clasificación va del grado 1 (femenino) al 5 (masculino) se le asignó un grado 4 . Es decir, el individuo sería probablemente masculino. Estos rasgos eran insuficientes para determinar el sexo, por lo que los parámetros métricos nos resultaron útiles (Bass, 2005 en White et al., 2012). Como puede observarse en la tabla 1, mientras las mediciones de las extremidades inferiores eran claramente masculinas, en las superiores había mayor discrepancia. Patrón que se repetía en el caso de las clavículas y la cavidad glenoidea. Por tanto, y por todo lo expuesto, identificamos al sujeto como probablemente masculino (White et al., 2012).

\begin{tabular}{|l|c|c|c|}
\hline \multicolumn{1}{|c|}{ PARÁMETRO } & LADO & MEDIDAS & SEXO \\
\hline $\begin{array}{l}\text { Diámetro de la cabeza } \\
\text { del fémur }\end{array}$ & Izquierdo & $51^{\prime} 3 \mathrm{~mm}$ & Masculino \\
\hline Cóndilo del fémur & Izquierdo & $84^{\prime} 5 \mathrm{~mm}$ & Masculino \\
\hline $\begin{array}{l}\text { Diámetro de la cabeza } \\
\text { del húmero }\end{array}$ & Derecho & $44^{\prime} 3 \mathrm{~mm}$ & No significativo \\
\hline $\begin{array}{l}\text { Diámetro de la cabeza } \\
\text { de radio }\end{array}$ & Izquierdo & $23^{\prime} 2 \mathrm{~mm}$ & Masculino \\
\hline $\begin{array}{l}\text { Cavidad glenoidea de } \\
\text { la escápula }\end{array}$ & Derecho & $28^{\prime} 5 \mathrm{~mm}$ & Masculino (?) \\
\hline $\begin{array}{l}\text { Largo máximo de } \\
\text { clavícula }\end{array}$ & Ambos & $145 \mathrm{y} 146 \mathrm{~mm}$ & No significativo \\
\hline
\end{tabular}

Tabla 1: Parámetros métricos para la determinación del sexo: 1. >48mm=Masculino, $<43 \mathrm{~mm}=$ Femenino; 2. $>76 \mathrm{~mm}=$ Masculino, $<74 \mathrm{~mm}=$ Femenino; 3. $>47 \mathrm{~mm}=$ Masculino, $<43 \mathrm{~mm}=$ Femenino; $4 .>23 \mathrm{~mm}=$ Masculino, $<21 \mathrm{~mm}=$ Femenino; 5. $>28.6 \mathrm{~mm}=$ Masculino, $<26.1 \mathrm{~mm}=$ Femenino; 6. $>150 \mathrm{~mm}=$ Masculino, <138mm=Femenino. / Sex determination using anthropometric measurements: $1 .>48 \mathrm{~mm}=$ Male, $<43 \mathrm{~mm}=$ Female; 2. $>76 \mathrm{~mm}=$ Male, $<74 \mathrm{~mm}=$ Female; $3 .>47 \mathrm{~mm}=$ Male, $<43 \mathrm{~mm}=$ Female; 4. $>23 \mathrm{~mm}=$ Male, $<21 \mathrm{~mm}=$ Female; $5 .>28.6 \mathrm{~mm}=$ Male, $<26.1 \mathrm{~mm}=$ Female; 6 . $>150 \mathrm{~mm}=$ Male, $<138 \mathrm{~mm}=$ Female.

b) Edad. Para realizar la estimación de la edad se tuvo en cuenta la fusión epifisiaria de las clavículas y la clasificación numérica establecida por Brothwell en torno al desgaste de los molares (Brothwell, 1981 en White et al., 2012). A pesar de que las clavículas presentaban un grado bastante alto de concreción pudimos corroborar que ambas tenían las epífisis y diáfisis soldadas. Este proceso se inicia en torno a los 21 años y finaliza sobre los 30 pero en la mayoría de los casos, siendo determinante la variabilidad biológica, se da antes de los 28 años (White et al., 2012). Dicho esto, y basándonos en las clavículas, la edad del individuo se situaría en torno a los 28 años. En lo que respecta al estudio del desgaste molar, y a pesar de que se cuestiona su fiabilidad, las piezas dentales analizadas pertenecían al maxilar inferior: M1, M2, M3 del lado derecho y M1 y M2 del izquierdo. Basándonos en la tabla de clasificación elaborada por Brothwell (Brothwell, 1981 en White et al., 2012: 390), donde establece hasta 7 grados (siendo 1 el menor grado -dientes sin desgaste- y el 7 el mayor -sólo conservan la raíz-), el desgaste molar identificado fue el siguiente: 4 para los M1, 3 para los M2 y 2 para el M3 derecho. La edad del individuo por tanto, estaría comprendida entre los 25-35 años de edad. Teniendo en cuenta todos estos parámetros, los restos óseos corresponderían a un adulto-joven.

c) Estatura. PPara estimar la altura empleamos los cálculos matemáticos planteados por Trotter y Gleser, basados en la medición de los huesos largos (Trotter y Gleser, 1958 en White et al., 2012). El fémur es el hueso largo más idóneo para estimar la estatura pero al no haberse recuperado en su totalidad ninguno de ellos (figura 6), tuvimos que recurrir a la tibia y el peroné que miden 350 y 335 $\mathrm{mm}$ respectivamente. Habiendo determinado que 


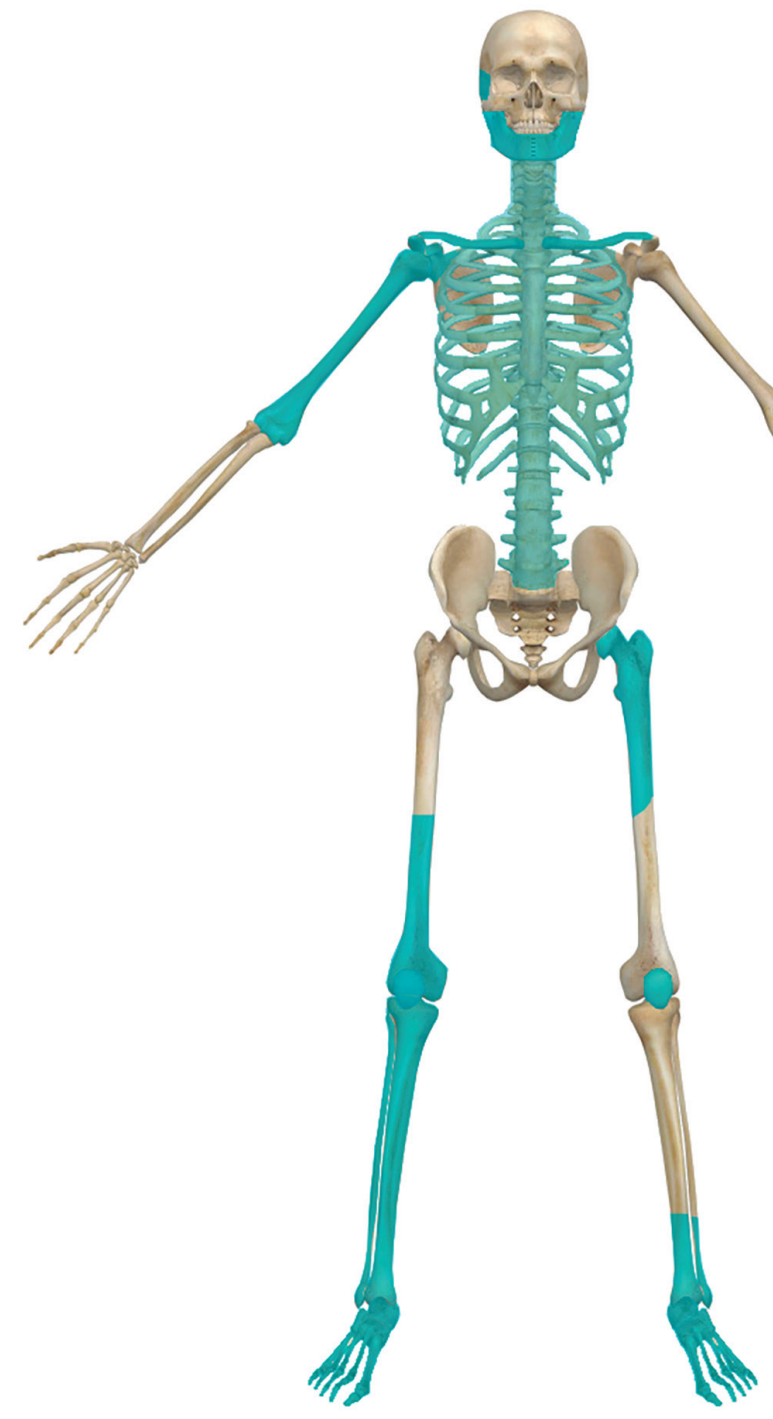

los huesos correspondían a un individuo masculino las fórmulas empleadas fueron las siguientes (debemos indicar que cada hueso tiene su propia ecuación matemática):

Tibia: 2'42 x (medida cm) + 81'43 = cm \pm 4'04

Peroné: 2'68 x (medida cm) + 71'78 = cm \pm 3'29

La estatura del individuo, según los cálculos basados en la tibia sería de 162'54-170'57 cm. Sin embargo, esta fórmula tendría un error de base al no tenerse en cuenta el maléolo medial (Jantz, 1993: 760) siendo el resultado obtenido, entre 2'5 a $3 \mathrm{~cm}$ menor. En lo que respecta al peroné, el rango de estatura obtenido ha sido de 158'27-164'85 cm.

\subsubsection{ANÁLISIS ISOTÓPICOS}

Nos parece oportuno, y debido a que su aplicación en estudios del País Vasco es relativamente reciente, externos en el desarrollo de este subapartado.
1. Fragmento de cráneo.

2. Temporal derecho.

3. Maxilar inferior fragmentado.

4. Piezas dentales: 11, 36, 37, 38, 45, 46 y 47.

5. Clavículas derecha e izquierda

6. Acromion, apófisis coracoides y cavidad glenoidea derecha.

7. Vertebras (dorsales -axis-, ventrales y lumbares) y fragmentos de vertebra.

8. Múltiples fragmentos de costilla.

9. Húmero derecho.

10. Radio izquierdo.

11. Epifisis superior e inferior del cúbito izquierdo.

12. Epífisis inferior del fémur derecho.

13. Rótula derecha.

14. Tibia derecha.

15. Peroné derecho.

16. Calcáneo y astrágalo derechos.

17. Metatarsos y falanges derechas.

18. Epífisis superior y parte de la diáfisis del fémur izquierdo.

19. Rótula izquierda.

20. Epífisis inferior de la tibia izquierda.

21. Epífisis inferior del peroné izquierdo.

22. Astrágalo, calcáneo y escafoides izquierdos.

23. Metatarsos y falanges izquierdos.

Fig. 6. Inventario simplificado de los restos humanos recuperados en Karea-B. En el esqueleto tipo se han marcado los huesos identificados. / Simplified inventory of bones recovered in Karea-B. Identified bones have been marked on the model skeleton.

\subsubsection{Análisis de isótopos estables de $\delta^{13} \mathrm{C}$ y $\delta^{15} \mathrm{~N}$}

UUna de las herramientas más comunes para la reconstrucción de dietas prehistóricas es la de los análisis de isótopos estables de carbono $\left(\delta^{13} \mathrm{C}\right)$ y nitrógeno $\left(\delta^{15} \mathrm{~N}\right)$ sobre colágeno óseo (Salazar-García y Silva Pinto, 2017). Esta técnica parte de la premisa de que la composición isotópica de los alimentos ingeridos durante los últimos años de vida se refleja en los tejidos del consumidor. Sin embargo, debemos considerar el fenómeno conocido como "fraccionamiento isotópico", que se produce por la elección diferencial de isótopos, siendo los más ligeros más móviles, aspecto que se refleja en los ratios isotópicos; por lo tanto, en este proceso los valores de $\delta^{13} \mathrm{C}$ pueden variar entre 0 y $1 \%$, y los de $\delta^{15} \mathrm{~N}$ entre 3 y $5 \%$, correspondiendo estos últimos a diferentes niveles tróficos (De Niro y Epstein, 1978, 1981; Schoeninger y De Niro, 1984). Los análisis de $\delta^{13} \mathrm{C}$ nos permiten conocer el peso relativo de las proteínas dependiendo de su origen (terrestre o marino), así como entre recursos $\mathrm{C}_{3} \circ \mathrm{C}_{4}$ (Tauber, 1981). En cuanto 
a los valores de $\delta^{15} \mathrm{~N}$, están relacionados con la complejidad de la cadena trófica del organismo analizado, que aumentan a lo largo de ella; de este modo, los de ecosistemas marinos tienen niveles $\delta^{15} \mathrm{~N}$ más elevados (Minawaga y Wada, 1984). Finalmente, en la interpretación de estos resultados debemos tener siempre en cuenta el enmascaramiento que sufren los valores de los recursos vegetales por parte de los faunísticos (Richards et al., 2003).

Para estos análisis se obtuvo el colágeno óseo siguiendo el método descrito por Longin (1971) y Richards y Hedges (1999) con un paso de ultrafiltración (Brown et al., 1988). Todas las muestras fueron analizadas por duplicado utilizando un espectrómetro de masas de ratios isotópicos de flujo continuo Delta plus XP (Thermo Fisher Scientific, EEUU), después de su combustión en un analizador elemental Flash EA 1112 (Thermo-Finnigan, Germany). Este proceso se llevó a cabo en los laboratorios de la University of Cape Town (Sudáfrica). Los ratios de isótopos estables se expresan en función de la escala V-PDB (Vienna Pee Dee Belemnite) para el caso del carbono, y de la escala AIR (atmospheric $\mathrm{N}_{2}$ ) para el nitrógeno, utilizando la notación delta $(\delta)$ en partes por mil (\%o). Los análisis replicados internos cumplen los estándares internacionales, y con un error analítico mejor que $0.1 \%$ (1б).

Para el estudio de los análisis sobre material óseo de Karea-B procedimos, en primer lugar, a la selección de una muestra del individuo inhumado. Para ello, to- mamos un fragmento de costilla de 500mg, puesto que se trata de un resto que no aporta valor antropológico reseñable y, sin embargo, debido a su estructura es útil en el proceso de obtención del colágeno óseo. Respecto a los restos faunísticos, fue posible muestrear un fragmento del cráneo de Bos taurus. De ambas muestras, tanto la humana como la faunística, conseguimos extraer suficiente colágeno óseo de fracción $>30 \mathrm{kDa}$ para poder realizar los análisis por duplicado. Todos los resultados cumplen con los baremos de control de calidad, según los cuales se estipula que los datos de $\%$ C deben ser $>30$, los de $\% \mathrm{~N}>10$ y que la ratio elemental C: $\mathrm{N}$ debe oscilar entre 2.9 y 3.6 (Ambrose, 1993; Van Kliken, 1999).

La única muestra faunística analizada nos aporta valores de $\delta^{13} \mathrm{C}$ de $-21.5 \%$ y $\delta^{15} \mathrm{~N} 4.2 \%$ o, los cuales coinciden con los datos que conocemos de estudios previos cercanos (Sarasketa-Gartzia et al., 2017) de ecosistemas terrestres tipo $\mathrm{C}_{3}$ (Van der Merwe y Vogel, 1978). Los resultados obtenidos tras el análisis sobre el colágeno de la muestra humana son los siguientes: $\delta^{13} \mathrm{C}$ de $-19.9 \%$ y $\delta^{15} \mathrm{~N}$ de $8.9 \%$ (ver tabla 2 y figura 7 ). Estos datos de $\delta^{13} \mathrm{C}$ coinciden con una dieta basada principalmente en alimentos de origen terrestre tipo $\mathrm{C}_{3}$. Los valores de $\delta^{15} \mathrm{~N}$, por su parte, muestran claramente al ser humano en un nivel trófico superior al resto faunístico analizado (4.5\% mayor), así como a otros restos faunísticos de otros yacimientos de la misma cronología que podemos utilizar a modo de comparativa (Sarasketa-Gartzia et al., 2017).

\begin{tabular}{|l|c|c|c|c|c|c|}
\hline \multicolumn{1}{|c|}{ Especie } & Muestra S-UCT & $\mathbf{\delta}^{13} \mathbf{C} \%$ & $\% \mathbf{C}$ & $\mathbf{\delta}^{15} \mathbf{N} \%$ & \% $\mathbf{N}$ & $\mathbf{C}: \mathbf{N}$ \\
\hline Humano & 18456 & -19.87 & 38.36 & 8.85 & 13.62 & 3.29 \\
\hline Bos taurus & 18457 & -21.54 & 35.33 & 4.15 & 12.53 & 3.29 \\
\hline
\end{tabular}

Tabla 2: Valores medios de $\delta^{13} \mathrm{C} \%$ y $\delta^{15} \mathrm{~N} \%$ y parámetros de calidad del colágeno (\%C, \%N y C:N) de las dos medidas analizadas para cada muestra. / Average values of $\delta^{13} \mathrm{C} \%$ y $\delta^{15} \mathrm{~N} \%$ and collagen quality parameters of the two measurements analyzed for each sample (\%C, \%N y C:N).

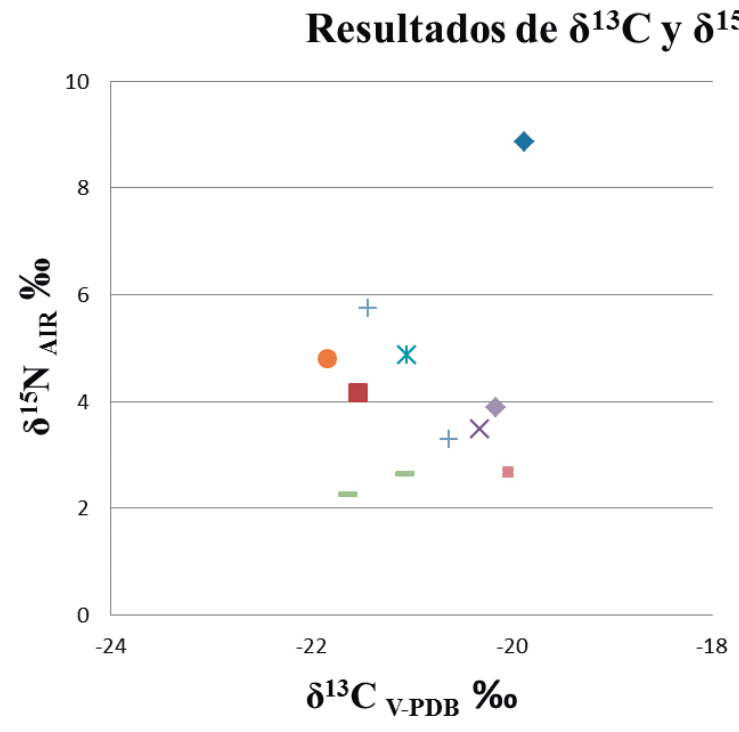

- Humano Karea

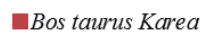

$\times$ Ovis aries/ Capra hircus PRA

* Sus scrofa PRA

- Bos taurus PRA

+ Ovis aries/ Capra hircus SANT

- Capra pyrenaica $S A N T$

- Cervus elaphus SANT

- Sus scrofa SANT

Fig. 7. Resultados de los valores isotópicos de $\delta^{13} \mathrm{C}$ y $\delta^{15} \mathrm{~N}$ del yacimiento de Karea y resultados faunísticos de los yacimientos de Santimamiñe y Pico Ramos. $/ \delta^{13} \mathrm{C}$ and $\delta^{15} \mathrm{~N}$ isotopic results of Karea site and faunistical results of Santimamiñe and Pico Ramos sites. 


\subsubsection{Análisis de isótopos de $\underline{87} \underline{\mathrm{Sr}} \stackrel{86}{\mathrm{Sr}}$}

Los análisis de isótopos de estroncio están basados en las proporciones de dos de sus isótopos $\left({ }^{87} \mathrm{Sr} /{ }^{86} \mathrm{Sr}\right)$ en diferentes zonas geológicas. Cada zona tiene unas proporciones concretas de estos dos isótopos de estroncio, entre 0.700 y 0.750 , debido a que el isótopo radiogénico de estroncio deriva de la descomposición del rubidio ( $\left.{ }^{87} \mathrm{Rb}\right)$ y, por lo tanto, depende de la antigüedad de la roca y de procesos geológicos. Como consecuencia, las rocas más antiguas tienen los valores más altos de estroncio, puesto que llevan más tiempo sufriendo la descomposición del ${ }^{87} \mathrm{Rb}$ (Bentley, 2006). Los valores de estroncio presentes en las rocas pasan a través de la cadena trófica hasta los tejidos corporales humanos, sin sufrir el fraccionamiento isotópico. En este estudio se ha tomado una muestra de esmalte y, además, muestras actuales de plantas y caracoles para establecer el estroncio biodisponible.

3.2.5.2.1 Análisis de ${ }^{87} \mathrm{Sr}{ }^{\beta 6} \mathrm{Sr}$ en muestras actuales: (1) Los caracoles se limpiaron manualmente, con agua destilada y un cepillo desechable, y tras un baño de ultrasonidos fueron trasladados al laboratorio limpio del Department of Geological Sciences de la University of Cape Town (Sudáfrica). Las muestras fueron introducidas en recipientes de teflón de $7 \mathrm{ml}$, para, a continuación recolectar el estroncio usando el sistema de separación química por columnas (Pin et al., 1994). (2) Las plantas, en cambio, fueron incineradas previo al mencionado proceso de recolección de estroncio por columnas.

Con el objetivo de generar una base de datos del estroncio biodisponible del entorno inmediato del yacimiento (Jurásico, Lias-Dogger; fuente: igme), se tomaron muestras actuales de cinco plantas (herbáceas y arbustivas) y cinco caracoles. Las taxones botánicos seleccionados fueron los siguientes: Smilax aspera, Hedera hélix, Cyatheales, Rosaceae, Poaceae. Todas las muestras de caracoles eran de la especie Helix aspersa.

3.2.5.2.2. Análisis de ${ }^{87} \mathrm{Sr}{ }^{\beta 6} \mathrm{Sr}$ en muestras arqueológicas: Tras la obtención y limpieza de, aproximadamente, 20mg de esmalte se procede a la digestión de la muestra en $\mathrm{HNO}_{3}$, y previo al proceso de columnas, fueron calculadas las concentraciones de Sr (Copeland et al., 2008), con el fin de establecer que no ha habido contaminación diagenética. La fracción fue finalmente diluida a una concentración de Sr 200 ppb para el análisis utilizando un Nu Instruments Un Plasma HR MC-ICP-MS. Los análisis fueron referenciados con NIST SRM987, usando el valor de referencia ${ }^{87} \mathrm{Sr} /{ }^{86} \mathrm{Sr}$ 0.710255 . Todos los datos de isótopos de estroncio fueron corregidos para la interferencia isobárica del rubidio 87 , la señal medida por ${ }^{85} \mathrm{Rb}$ y el ratio natural ${ }^{85} \mathrm{Rb} /{ }^{87} \mathrm{Rb}$. El fraccionamiento de masa instrumental fue corregido usando el ratio medido de ${ }^{86} \mathrm{Sr} /{ }^{88} \mathrm{Sr}$ y la ley exponencial y el valor real de ${ }^{86} \mathrm{Sr} / 88 \mathrm{Sr}$ de 0.1194 , los ratios ${ }^{84} \mathrm{Sr} /{ }^{66} \mathrm{Sr}$ representados en la tabla 3 entran dentro de los parámetros esperados.
Para proceder con el análisis de isótopos de estroncio se muestreó un segundo molar, del cual se tomaron $20 \mathrm{mg}$ de esmalte dentario tras eliminar la capa superficial del mismo mediante una fresa pulidora de diamante acoplada a un Dremmel.

\begin{tabular}{|c|c|c|c|c|c|}
\hline $\begin{array}{c}\text { Muestra } \\
\text { S-UCT }\end{array}$ & Material & $\begin{array}{c}\text { Concen- } \\
\text { tración } \\
\text { Sr (ppm) }\end{array}$ & ${ }^{84} \mathbf{S r}{ }^{86} \mathbf{S r}$ & $\mathbf{S r}(\mathbf{V})$ & ${ }^{87} \mathbf{S r}{ }^{86} \mathrm{Sr}$ \\
\hline 18103 & Smilax aspera & - & 0.056574 & 7.91 & 0.708609 \\
\hline 18104 & Hedera hélix & - & 0.056545 & 7.79 & 0.708796 \\
\hline 18105 & Cyatheales & - & 0.056542 & 7.08 & 0.708956 \\
\hline 18106 & Rosaceae & - & 0.056308 & 5.56 & 0.709630 \\
\hline 18107 & Poaceae & - & 0.056546 & 6.15 & 0.709657 \\
\hline 18204 & Caracol & - & 0.056602 & 8.79 & 0.708452 \\
\hline 18205 & Caracol & - & 0.056563 & 7.37 & 0.708281 \\
\hline 18206 & Caracol & - & 0.056648 & 6.74 & 0.708542 \\
\hline 18207 & Caracol & - & 0.056552 & 6.03 & 0.708520 \\
\hline 18208 & Caracol & - & 0.056567 & 7.11 & 0.708737 \\
\hline 18265 & M2 Humano & 73.77 & 0.056587 & 7.17 & 0.708398 \\
\hline
\end{tabular}

Tabla 3: Lista de las muestras actuales y muestra fósil de Karea. Las concentraciones han sido realizadas únicamente en la muestra fósil con el fin de comprobar su estado de preservación. / List of current samples and sample of Karea. In order to verify it state of preservation only Karea concentrations have been analyzed.

Los resultados de ${ }^{87} \mathrm{Sr} /{ }^{86} \mathrm{Sr}$ de las muestras actuales de plantas y caracoles $(n=10)$ para el cálculo de los valores biodisponibles del entorno geológico del yacimiento de Karea, que se abre sobre un substrato del Jurásico, se encuentran en el rango de $0.708737 \pm 0.000474(1 \sigma)$ como se ve ilustrado en la tabla 3. El resultado isotópico de estroncio obtenido para la muestra de molar (0.708398) coincide plenamente con el rango biodisponible obtenido, tal y como podemos observar en la figura 8.

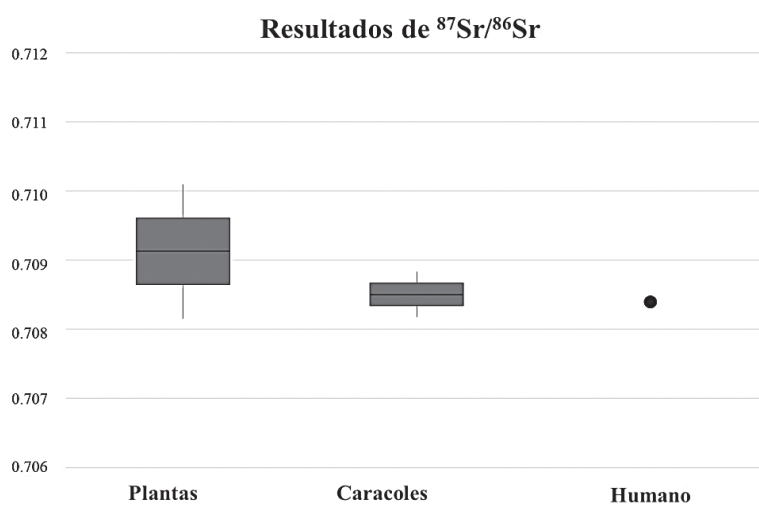

Fig. 8. Resultados de los ratios isotópicos de ${ }^{87} \mathrm{Sr} /{ }^{86} \mathrm{Sr}$ de las plantas, caracoles y la muestra dentaria humana. / Results of ${ }^{87} \mathrm{Sr} /{ }^{86} \mathrm{Sr}$ isotopic ratios of plants, snails and human tooth sample. 


\section{DATACIÓN MEDIANTE ${ }^{14} \mathrm{C}$}

La datación de ${ }^{14} \mathrm{C}$ fue realizada sobre un fragmento de costilla del individuo que fue recogida in situ. Dicha muestra fue procesada por la Oxford Radiocarbon Accelerator Unit (ORAU) de la University of Oxford (Reino Unido) que dio como resultado una fecha radiocarbónica de $4125 \pm 35$ años (4686 \pm 96 cal BP). Fecha que correspondería a época Calcolítica (figura 9).

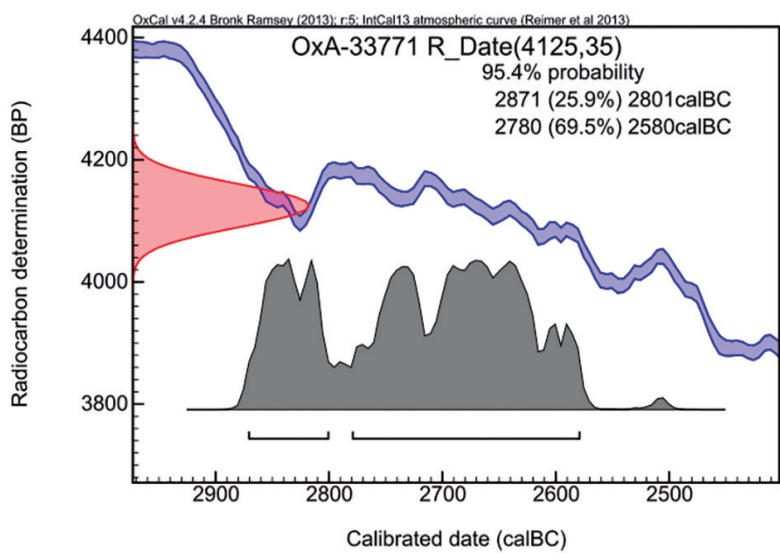

Fig. 9. Gráfica de calibración de Karea-B. / Calibration graph of Karea-B.

\section{DISCUSIÓN}

Concluido el estudio material de Karea podemos afirmar que estamos frente a un yacimiento de finalidad dual cuyo marco cronológico comprende cronologías del Calcolítico a la Edad del Bronce. A pesar de haber obtenido una datación de ${ }^{14} \mathrm{C}$ que sitúa la inhumación de Karea-B en época Calcolítica, en lo que respecta a Karea-A no ha podido establecerse cronología absoluta. Por ello, hemos tenido que basarnos en las características de los fragmentos cerámicos recuperados y a modo de cronología relativa establecer que el depósito de Karea-A estaría más próximo a la Edad del Bronce. Por este motivo, y teniendo en cuenta el yacimiento en todo su conjunto, hemos consensuado que lo adecuado es situar la cronología de Karea dentro de una horquilla cultural amplia (Gorrotxategi y Yarritu, 1990).

Los restos arqueológicos recuperados en Karea-A parecen indicar que la ocupación de la misma fue breve y puntual. Este tipo de ocupaciones temporales se han documentado durante el Neolítico y la Edad de los Metales en cuevas como Anton Koba (Aranzazu), Lokatza (Ataun) o Ermittia (Deba) (Altuna et al., 1982, 1995) y han sido atribuidas a grupos ganaderos trashumantes (Edeso et al., 2010; Edeso y Mujika, 2012). Es muy probable, por lo tanto, y a falta de estudios que aporten más información de la zona, que la ocupación de Karea-A se diese por parte de grupos ganaderos trashumantes de la Edad del Bronce. Este planteamiento se ve reforzado si tenemos en cuenta que Karea está situada en un emplazamiento próximo a los valles fluvia- les del Urola y el Oria, y que con las mejoras climáticas del Holoceno sería un buen enclave para llevar a cabo diversas actividades como, por ejemplo, la ganadería (Ontañón y Armendariz, 2005). Asimismo, las propias características de la cueva la convertirían en un buen lugar donde establecer un refugio temporal ya que la entrada era accesible y la galería adecuada para albergar a un pequeño grupo de personas. En cronologías de la Edad del Bronce y en el Valle del Urola podríamos establecer paralelismos con Danbolin (Zestoa), Aitze (Zestoa) o Urkitte-Aitz II (Azkoitia), entre otras (Altuna et al., 1982, 1995).

La actividad de estos grupos ganaderos trashumantes es posiblemente uno de los factores que determine la presencia de cuevas de carácter sepulcral en zonas de montaña (Mujika y Edeso, 2011). Estos grupos, en determinados momentos, se verían en la necesidad de llevar a cabo alguna inhumación y teniendo en cuenta que ocupaban zonas kársticas, es lógico pensar que hiciesen uso de cuevas próximas o incluso de aquellas que habitaban o habían habitado (Edeso y Mujika, 2012). Por tanto, y en relación a esto último, pueden identificarse diferentes modelos de ocupación o uso. Armendáriz y Etxeberria (1995), por ejemplo, establecen tres modelos: 1) cavidades con uso habitacional y funerario superpuesto; 2) aquellas que contienen ocupación y uso funerario contemporáneo y 3) cuevas de uso exclusivamente funerario. Por otra parte, Sarobe (2012) señala que pueden identificarse dos tipos de cavidades sepulcrales: a) cuevas amplias y de fácil acceso que tienen espacios habitacionales y b) cuevas estrechas y de difícil acceso, donde solo se da la presencia de enterramientos. En lo referente a Karea, suponiendo que el derrumbe que separó Kare-A y Karea-B se dio en fechas posteriores y en base a las cronologías establecidas, estaríamos frente a una cueva amplia de fácil acceso y donde se superponen una inhumación calcolítica y una ocupación breve de la Edad del Bronce. En lo que respecta a la localización de los depósitos funerarios dentro de las cuevas y aunque puedan observarse ubicaciones, dimensiones u orientaciones diversas, queda de manifiesto que los grupos humanos tenían cierta tendencia a depositar los cuerpos en pequeños lugares intrínsecos y/o de difícil acceso con la intención de proteger o resguardar los cuerpos (Armendariz, 1983, 1992, 1997, 1999; Armendariz y Etxeberria, 1983). Es probable, y a pesar de que se propone de manera generalizada que depositaban los cuerpos directamente en el suelo, que adecuasen la zona para proteger el depósito funerario: construcción de muretes, estructura de madera... (Mujika y Edeso, 2011). La ubicación de la inhumación de Karea-B en una gatera lateral estrecha y alejada de la entrada, junto a no ser detectable a primera vista, corrobora esa tendencia de proteger el cadáver; tendencia que también puede observarse en cavidades de cronología alcolítica como Amalda IV (Zestoa), Astui-Gaina (Zestoa) o Akaitztxiki II (Enirio-Aralar), entre otras (Altuna et al, 
1995). En lo referente a la presencia de estructuras en Karea-B, tenemos que indicar que no se detectó ningún vestigio de ello.

Los estudios antropológicos realizados sobre los restos humanos de Karea-B por su parte, dejan de manifiesto que se depositó un único cadáver, al igual que en las ya citadas Amalda IV (Zestoa) o Astui-Gaina (Zestoa). Las cuevas sepulcrales sin embargo, y por norma general, eran empleadas para albergar inhumaciones colectivas (Armendariz, 1990, 1992; Armendariz y Etxeberria, 1995), siendo ejemplo de ello Jentiletxeta I (Mutriku), Iruaxpe I (Aretxabaleta) o Urtao II (Oñati) (Altuna et al, 1995). Esta diferenciación en el número de personas inhumadas, no obstante, podría estar relacionada con la propia composición de los grupos. Las cuevas con un único o escaso número de individuos, como sería Karea, podrían tener relación con pequeñas agrupaciones humanas cuya ocupación de la zona fuese, posiblemente, puntual; por el contrario, las cavidades sepulcrales donde el número de inhumados es mayor, podrían ser reflejo de grupos humanos de mayor tamaño que llevaron a cabo una ocupación más prolongada o intensa de la zona (Edeso et al., 2010; Mujika y Edeso, 2011). Por otra parte, e independientemente del número de personas inhumadas, ha podido determinarse que en las cuevas sepulcrales no hay sesgos en relación al sexo o la edad (Ontañón y Armendáriz, 2005). Al hilo de esto, y retomando los datos del estudio antropológico, podemos establecer que el individuo de Karea-B se trataría de un hombre joven del Calcolítico que, y teniendo en cuenta lo expuesto en este apartado, pudo pertenecer a un pequeño grupo que se encontraba de pastoreo o de paso por la zona de Karea (a falta de estudios que, como ya hemos dicho anteriormente, aporten más información en torno a la zona y las dinámicas de los grupos humanos).

En lo referente a los resultados de isótopos de $\delta^{13} \mathrm{C}$ y $\delta^{15} \mathrm{~N}$ de Karea-B, estos muestran un consumo mayoritario de proteínas de origen terrestre tipo $\mathrm{C}_{3}$, coherente con los patrones de alimentación esperables para esta cronología. A nivel isotópico, no hay rastro de consumo de recursos marinos, y posiblemente tampoco de recursos de agua dulce, a pesar de la cercanía a los recursos fluviales de los ríos de Irueta y Bero, ambos afluentes del río San Pedro que desemboca en el Oria. Esto no quiere decir que no consumieran recursos acuáticos, sino que no lo hacían en cantidades suficientes como para reflejarse en la signatura del colágeno óseo. Respecto a la relación de estos resultados con los obtenidos en otras investigaciones en zonas cercanas, podemos afirmar que encajan a la perfección con los datos previos: con Pico Ramos y Santimamiñe de la costa vizcaína (Sarasketa-Gartzia et al., 2017), con el yacimiento neolítico de Cotero de la Mina y el de la Edad de Bronce La Garma A en Cantabria (Arias, 2005), con los alaveses Fuente Hoz y Kurtzebide (Sarasketa-Gartzia et al., 2018) por un lado, y Las Yurdinas II, Los Husos, Peña Larga, El Sotillo, Alto de la Huesera, La Chabola de la Hechicera y Longar por otro (Fernández-Crespo y Schulting, 2017) y finalmente el único yacimiento de Gipuzkoa publicado hasta el momento, el yacimiento de Ondarre de la Edad de Bronce (Fernández-Crespo et al., 2016). Todos ellos muestran un consumo mayoritario de alimentos terrestres de tipo $\mathrm{C}_{3}$, con pequeñas variaciones, para cronologías postneolíticas. Es reseñable, por lo tanto, que a partir del Neolítico el ser humano parece dar la espalda a la costa y a sus posibles recursos, incluso encontrándose a pocos kilómetros de la misma; tal y como hemos podido comprobar, no sólo en Karea sino también en otros yacimientos costeros como los mencionados Pico Ramos y Santimamiñe.

Los resultados de ratios de isótopos de estroncio, por su parte, serían compatibles con que el individuo viviera durante su infancia en el entorno geológico en que se enmarca el yacimiento, o bien con otras zonas de afloramiento del Jurásico (teniendo en cuenta que el molar analizado se trata de un M2, cuyo periodo de mineralización se desarrolla entre el nacimiento y los 10 meses de edad (Bentley, 2006). Este patrón lo podemos relacionar, al igual que lo que ocurre con los resultados de isótopos estables de carbono y nitrógeno, con la hipótesis tradicional que ha caracterizado el periodo Calcolítico con el sedentarismo. Desgraciadamente, los análisis de estroncio en Gipuzkoa son inexistentes para cronologías prehistóricas, por lo que no es posible establecer relaciones entre resultados de diferentes yacimientos de la zona cercana. Sin embargo, podemos comparar los datos expuestos en el presente artículo con los realizados en los yacimientos de Pico Ramos y Santimamiñe en Bizkaia (Sarasketa-Gartzia et al., 2017), los alaveses Fuente Hoz y Kurtzebide (Sarasketa-Gartzia et al., 2018) y el yacimiento aragonés de la cueva de San Juan (Villalba-Mouco et al., 2017). Si tenemos en cuenta estos datos, observamos diferentes patrones en función de la zona geográfica. Si bien así como los yacimientos vizcaínos y alaveses destacan por su alto grado de movilidad, menos de un 20\% de los individuos del yacimiento aragonés mostraron valores de estroncio alóctonos. Por lo tanto, debemos reseñar la alta variabilidad y aparente contradicción en los patrones de movilidad de los diferentes individuos analizados hasta ahora en las zonas cercanas para esta cronología.

Para finalizar con este apartado, nos centraremos en los restos faunísticos y cerámicos recuperados, así como en los vestigios de fuego detectados en el depósito funerario de Karea-B. La presencia de fragmentos cerámicos en los ajuares de las cuevas sepulcrales sería un hecho habitual (Apellániz, 1975) y en el caso de Karea-B así se verifica, habiéndose recuperado varios fragmentos que corresponderían a dos recipientes decorados de tamaño considerable. La decoración y tipología de estos sin embargo, parecen contradecir la cronología calcolítica obtenida por la datación de ${ }^{14} \mathrm{C}$, ya que la forma carenada de uno y la decoración plástica del otro, encajarían mejor en cronologías del 
Bronce. Esto en principio, resulta contradictorio pero teniendo en cuenta la ocupación de la Edad del Bronce de Karea-A, estos fragmentos pudieron ser depositados por ese mismo grupo. Si partimos de la base de que los grupos ganaderos podían recurrir de manera sistemática a zonas que conocían (Edeso et al., 2010; Edeso y Mujika, 2012) podrían conocer la existencia de la inhumación previa; y por ello, a la vez que habitaron la cueva, depositar la cerámica. En lo referente a los restos faunísticos recuperados en los ajuares funerarios de las cuevas sepulcrales, se aprecia una selección de piezas donde priman los huesos largos, y que según Apellániz (1975) se daría de manera intencionada. En el caso de Karea-B se confirma la preferencia de huesos largos pero no podemos afirmar si hubo intencionalidad en esa selección. En lo que respecta a las especies identificadas, Bos taurus y un ovicáprido, su presencia podría estar relacionada, una vez más, con las características de los grupos humanos ya que durante el Calcolítico el ganado mayoritariamente era ovino, y en cronologías posteriores como el Bronce, predominó el bovino (Edeso y Mujika, 2010). Asumiendo que este fuese el ajuar funerario, podemos concluir que se trataba de un conjunto modesto. Armendariz y Etxeberria (1995) destacan el carácter selectivo y modesto de los ajuares recuperados en las cuevas sepulcrales guipuzcoanas como Aintzulo (Errezil), Amalda IV (Zestoa) o Astui-Gaina (Zestoa) (Altuna et al., 1995). Debemos incidir a su vez, que no debe desecharse la posibilidad de que se depositasen elementos de carácter perecedero junto a los cadáveres y que por lo tanto, no tengamos una representación real de los mismos.

Respecto a la presencia de carbón previo a la inhumación de Karea-B, se podría plantear que el cadáver en cuestión hubiese sido cremado o incinerado. Sin embargo, y en el caso que nos ocupa, no se aprecian alteraciones térmicas o fracturas de los huesos por exposición al fuego (Fernández-Crespo, 2016). Dicha alteración tampoco se ha detectado en los restos cerámicos ni faunísticos. Por tanto, quedaría descartada la práctica de cremación o incineración del cuerpo, dando pie a otro tipo de interpretaciones. En relación a la presencia de fuego en cuevas sepulcrales, Apellániz (1975) plantea el uso de este como una práctica funeraria ritual, mientras que Andrés $(1977,1979)$ lo interpreta como una medida de orden práctico para albergar futuras inhumaciones. Ontañón y Armendariz por su parte (2005), exponen que a pesar de haberse encontrado en alguna ocasión señales de ello, no hay constancia de que se realizasen cremaciones en estos contextos sepulcrales de manera sistemática.

\section{CONCLUSIONES}

El yacimiento de Karea está compuesto por una inhumación calcolítica y una ocupación de baja intensidad de la Edad del Bronce. En lo que respecta al depósito funerario, vemos que sigue la tendencia de otras cuevas del Valle del Urola al ser un depósito funerario de un único individuo, situado en un espacio reducido de difícil acceso, y con un ajuar modesto. Los análisis isotópicos realizados al individuo de Karea, dejan patente la importancia de los recursos terrestres tipo $\mathrm{C}_{3}$ en la alimentación del mismo. De igual manera, los datos obtenidos de estroncio muestran una posible procedencia local del individuo, coherente con lo esperado en una cronología calcolítica. La presencia de carbones en los niveles previos al depósito funerario resulta interesante ya que, ni en los huesos humanos ni en el resto de materiales recuperados, se aprecia exposición al fuego, pudiendo haberse empleado con fines higiénicos o rituales. La ocupación del Bronce por su parte, correspondería a una breve y puntual estancia por parte de grupos ganaderos trashumantes.

La cueva de Karea no solo aporta información que corrobora las teorías expuestas a partir del estudio de otras cavidades de carácter sepulcral. Su descubrimiento también pone de manifiesto que todavía desconocemos parte de la prehistoria guipuzcoana. Se espera que, en futuras investigaciones y a medida que avancen las excavaciones en esta zona, podamos obtener más datos en torno a los comportamientos y dinámicas sociales de estos grupos, además de generar un corpus de datos isotópicos de las diferentes zonas geográficas del tercio norte peninsular, que nos ayuden a comprender los patrones de alimentación y movilidad territorial en la Prehistoria de la región. Por tanto, y como ya han manifestado otros investigadores con anterioridad (Armendáriz y Etxeberria, 1983; Sarobe, 2012), vemos necesario impulsar la investigación de este tipo de cavidades, no solo con el fin de darlas a conocer, sino de completar la Prehistoria guipuzcoana desde un punto de vista más amplio. Para ello, es necesario impulsar y publicar los estudios multidisciplinares de aquellos materiales recuperados en intervenciones arqueológicas.

\section{AGRADECIMIENTOS}

Este trabajo constituyó el nicho de la TFM de la primera firmante en el Máster de Cuaternario: Cambios Ambientales y Huella Humana de la Universidad del País Vasco/Euskal Herriko Unibertsitatea. AAM e ISG se benefician de una beca predoctoral concedida por el Gobierno Vasco. AAM, ISG y AA están parcialmente financiados por el proyecto de investigación del Ministerio de Ciencia e Innovación de España HAR201453536-P (La ruta occidental del poblamiento de la Península Ibérica durante el Paleolítico medio y superior), y el Grupo de Investigación de Prehistoria de la Universidad del País Vasco (IT-622-13). Especial agradecimiento a Vanessa Villalba, Fayrooza Rawoot, Kerryn Gray e Ian Newton por la asistencia técnica, y a Christel Tinguely por los valores de las concentraciones de Sr. Gracias también a E. Azpeitia por su colaboración en la localización del yacimiento. 


\section{BIBLIOGRAFÍA}

Altuna, J.; Armendariz, A., Barrio, L. Del, Etxeberria, F., Mariezkurrena, K., Zumalabe, F. J. y Peñalver, J., 1982. Carta Arqueológica de Gipuzkoa. Munibe 34, 1-242.

Altuna, J.; Armendariz, A., Barrio, L. Del, Etxeberria, F., Mariezkurrena, K., Zumalabe, F. J. y Peñalver, J., 1995. Carta Arqueológica de Gipuzkoa. II. Cuevas. Munibe Antropología-Arqueología, Suplemento 10.

Ambrose, S.H., 1993. Isotopic analysis of paleodiets: methodological and interpretative considerations. In: Stanford, M.K. (Ed.), Investigations of Ancient Human Tissue: Chemical Analyses in Anthropology. Gordon and Breach Science Publishers, Langhorne, 59-130.

Andrés, M.T., 1977. Las estructuras funerarias del Neolítico y Eneolítico en la Cuenca Media del Ebro. Príncipe de Viana $146 / 147$.

Andrés, M.T., 1979. Ritos funerarios de la Cuenca Media del Ebro. Neolítico y Eneolítico. Berceo 97, 3-25

Antxieta Jakintza Taldea, 2009. C. Gipuzkoa, C.31. Varios, C.31.8. Ikuluteko Gaiñe y Cueva de Karea (Aia, Gipuzkoa). Arkeoikuska 2008, 453. Departamento de Cultura, Eusko Jaurlaritza.

Apellániz, J.M., 1973. Corpus de materiales de las culturas prehistóricas con cerámica de la población de cavernas del País Vasco meridional. Munibe Ciencias Naturales, Suplemento $1,1-361$

Apellániz, J.M., 1975. El grupo de Santimamiñe durante la Prehistoria con cerámica. Munibe Antropología-Arqueología 27, Fascículo 1-2, 2-132.

Armendariz, A., 1988. Vaso campaniforme cordado de la cueva de Amalda II (Cestona, Gipuzkoa). Munibe Antropología-Arqueología 40, 83-88.

Armendariz, A., 1990. Las cuevas sepulcrales en el País Vasco. Munibe Antropología-Arqueología 42, 153-160.

Armendariz, A., 1992. La idea de la muerte y los rituales funerarios durante la Prehistoria en el País Vasco. Munibe Antropología-Arqueología, Suplemento 8, 13-22.

Armendariz, A., 1994. El mundo funerario en épocas prehistóricas. Cuadernos de Sección, Ciencias Médicas 3, 161-167.

Armendariz, A., 1997. Neolítico y Calcolítico en el País Vasco Peninsular. Isturitz 7, 23-36.

Armendariz, A. y Etxeberria, F., 1983. Las cuevas sepulcrales de la Edad de Bronce en Gipuzkoa. Munibe Antropología-Arqueología 35, 247-354.

Armendariz, A. y Etxeberria, F., 1995. Revisión del fenómeno funerario en las cuevas sepulcrales del País Vasco. In: Bertranpetit, J., Vives, E. (Ed.), Muntayes i Població. El passat dels Pirineus des d'una perspectiva multidisciplinària. Centre de Trobada de les Cultures Pirinenques.

Bentley, R., 2006. Strontium isotopes from the Earth to the Archaeological Skeleton: A Review. Journal of Archaeological Method and Theory 13, 135-187.

Brothwell, D.R., 1981. Digging up bones (3rd ed.). Cornell University Press, Ithaca, New York.

Brown, T.A., Nelson, D.E., Vogel, J.S. y Southon, J.R., 1988. Improved Collagen Extraction by Modified Longin Method. Radiocarbon 30, 171-177.

Caruso-Fermé, L., 2013. Los recursos vegetales en arqueología. Editorial Dunken, Buenos Aires.
Copeland, S.R., Sponheimer, M., LeRoux, P.J., Grimes, V., Lee-Thorp, J.A., De Ruiter, D.J. y Richards, M.P., 2008. Strontium isotope ratios $\left({ }^{87} \mathrm{Sr} /{ }^{86} \mathrm{Sr}\right)$ of tooth enamel: a comparison of solution and laser ablation multicollector inductively coupled plasma mass spectrometry methods. Rapid communications in mass spectrometry 22, 3187-3194.

De Niro, M.J. y Epstein S., 1978. Influence of diet on the distribution of carbon isotopes in animals. Geochimica et Cosmochimica Acta 42, 495-506.

De Niro, M.J. y Epstein S., 1981. Influence of diet on the distribution of nitrogen isotopes in animals. Geochimica et Cosmochimica Acta 45, 341-351.

Edeso, J.M., Mendizábal. M y Mujika, J.A., 2010. Estrategias de gestión de los recursos de montaña por las poblaciones dolménicas y contemporáneos en el Pirineo Occidental en: Fernández Eraso, J. y Mujika J.A. (coord.), 2010. Actas del Congreso Internacional sobre Megalitismo y Otras Manifestaciones Funerarias Contemporáneas en su Contexto Social, Económico y Cultural. Munibe, Suplemento 32, 368-388.

Edeso, J.M. y Mujika, J.A., 2012. Megalitismo y cuevas sepulcrales en Gipuzkoa. Distribución espacial y características generales. Isturitz 12, 83-114.

Fernández-Crespo, T., 2016. El papel del fuego en los enterramientos neolíticos finales/calcolíticos iniciales de los abrigos de la Sierra de Cantabria y sus estribaciones (valle medio-alto del Ebro). Trabajos de Prehistoria 73 (1), 128-146.

Fernández-Crespo, T., Mujika, J.A. y Ordoño, J. (2016). Aproximación al patrón alimentario de los inhumados en la cista de la Edad del Bronce de Ondarre (Aralar, Guipúzcoa) a través del análisis de isótopos estables de carbono y nitrógeno sobre colágeno óseo. Trabajos de Prehistoria 73 (2), 325-334.

Fernández-Crespo, T. y Schulting, R.J. (2017). Living different lives: early social differentiation identified through linking mortuary and isotopic variability in Late Neolithic/Early Chalcolithic north-central Spain. PlosOne 12(9), e0177881.

France, D.L., 2009. Human and Nonhuman Bone Identification. A Color Atlas. CRC Press, United States.

Gorrotxategi, J. y Yarritu, M.J., 1990. El Complejo Cultural del Neolítico Final-Edad del Bronce en el País Vasco Cantábrico. Munibe Antropología-Arqueología 42, 107-123.

Iriarte-Chiapusso, M. J., 2010. C. Gipuzkoa, C.1. Aia, C.1.2. Cueva de Karea. Arkeoikuska 2009, 325. Departamento de Cultura, Eusko Jaurlaritza.

Jantz, R. L.,1993. Modifying stature estimation from the femur and tibia: Author's response. Journal of Forensic Sciences 38:760-763.

König, H.E. y Liebich, H.G., 2004. Anatomía de los animales domésticos. Tomo 1: Aparato Locomotor. Editorial Médica Panamericana, Argentina.

Longin, R. 1971. New Method of Collagen Extraction for Radiocarbon Dating. Nature 230, 241-242.

Minawaga, M. y Wada, E., 1984. Stepwise enrichment of $15 \mathrm{~N}$ along food chains: further evidence and the relation between $15 \mathrm{~N}$ and animal age. Geochimica et Cosmochimica Acta 48, 1135-1140

Mujika, J.A. y Edeso, J.M., 2011. Los primeros agricultores y ganaderos trashumantes en Gipuzkoa del Neolítico a la Edad del Hierro. Diputación Foral de Gipuzkoa, Donostia.

Ontañón, R. y Armendariz, A., 2005. Cuevas y megalitos: los contextos sepulcrales colectivos en la Prehistoria reciente Cantábrica. Munibe Antropología-Arqueología 57, 275-286. 
Pin, C., Briot, D., Bassin, C. y Poitrasson, F., 1994. Concomitant separation of strontium and samarium-neodymium for isotopic analysis in silicate samples, based on specific extraction chromatography. Analytica Chimica Acta 298, 209-217.

Richards, M.P., Douglas, T., Koch, E., 2003. Mesolithic and Neolithic subsistence in Denmark: New isotope data. Current Anthropology 44 (2), 288-295.

Richards, M.P. y Hedges, R.E.M. 1999. Stable isotope evidence for similarities in the types of marine foods used by Late Mesolithic humans at sites along the Atlantic Coast of Europe. Journal of Archaeological Science 26, 712-722.

Salazar-García, D.C., 2009. Estudio de la dieta en la población neolítica de Costamar. Resultados preliminares de análisis de isótopos estables de carbono y nitrógeno. In: Flors, E. (Coord.), Monografíes de Prehistòria i Arqueologia Castellonenque, 8: Torre la Sal (Ribera de Cabanes, Castellón), evolución del paisaje antrópico desde la prehistoria hasta el Medievo, 411-418. Servei d' investigacions arquèologiques i prehistòriques, Castelló

Salazar-García, D.C. y Silva Pinto, V., 2017. Isótopos en la Prehistoria y Arqueología Valencianas. Saguntum Extra 19, 75-91.

Sarasketa-Gartzia, I., Villalba-Mouco, V., Le Roux, P., Arrizabalaga, A. y Salazar-García, D.C., 2017. Late Neolithic-Chalcolithic socio-economical dynamics in northern Iberia. A multi-isotope study on diet and provenance from Santimamiñe and Pico Ramos archaeological sites (Basque Country, Spain). Quaternary International 481, 14-27.

Sarasketa-Gartzia, I., Villalba-Mouco, V., Le Roux, P., Arrizabalaga, A. y Salazar-García, D.C., 2018. Anthropic resource exploitation and use of the territory at the onset of social complexity in the Western Pyrenees: a multi-isotope approach. Archaeological and Anthropological Science. Springer Special Issue. https://doi.org/10.1007/s12520-018-0678-7

Sarobe, O., 2012. La investigación de las cuevas sepulcrales de Gipuzkoa. Pasado, presente y futuro. In: Fernández Eraso, J.M.; Mujika, J.A., Actas del Congreso Internacional sobre Megalitismo y otras manifestaciones funerarias contemporáneas en su contexto social, económico y cultural. Munibe Antropología-Arqueología, Suplemento 32, 598-605.

Schoeninger, M.J. y De Niro, M.J., 1984. Nitrogen and carbon isotopic composition of bone collagen from marine and terrestrial animals. Geochimica et Cosmochimica Acta, 48, 625-639.
Schweingruber, F.H., 1990. Mikroskopische Holzanatomie. Eidgenössische Forschungsanstalt für Wald, Schneeund Lanschaft, Birmensdorf

Tapia, J., Ceberio, M., 2011. Los yacimientos en cueva de Gipuzkoa. Un balance de su estado de conservación. Munibe Antropología-Arqueología 62, 499-515.

Tauber, H. 1981. ${ }^{13} \mathrm{C}$ evidence for dietary habits of prehistoric man in Denmark. Nature 292, 332-333.

Trotter, M. y Gleser, G.C., 1958. A re-evaluation of estimation of stature based on measurements of stature taken during life and of long bones after death. American Journal of Physical Anthropology 16: 79-123.

Van der Merwe, N.J. y Vogel, J.C., 1978. ${ }^{13} \mathrm{C}$ content of human collagen as a measure of Prehistoric diet in Woodland North America. Nature 276, 815-816.

Van Klinken, G.J., 1999. Bone collagen quality indicators for palaeodietary and radiocarbon measurements. Journal of Archaeological Science 26, 687-695.

Villalba-Mouco, V., Sauqué, V., Sarasketa-Gartzia, I., Pastor, M.V., le Roux, P.J., Vicente, D., Utrilla, P. y Salazar-García, D.C. 2017. Territorial mobility and subsistence strategies during the Ebro Basin Late Neolithic-Chacolithic: a multi-isotope approach from San Juan cave (Loarre, Spain). Quaternary International 481, 28-41.

Walker, P.L., 2008. Sexing skulls using discriminant function analysis of visually assessed traits. American Journal of Physical Anthropology 136:39-50.

White, T.D., Black, M.T. y Folkens, P.A., 2012. Human osteology. Elsevier Academic Press, Amsterdam.

Zapata, L. y Peña-Chocarro, L., 2013. Macrorrestos vegetales arqueológicos en: García Díez, M.; Zapata, L. (Eds.), Métodos y técnicas de análisis y estudio en arqueología prehistórica. De lo técnico a la reconstrucción de los grupos humanos, 307318. Euskal Herriko Unibertsitatea Argitalpen Zerbitzua, Leioa. 